\title{
Genetic architecture underlying convergent evolution of egg-laying behavior in a seed-feeding beetle
}

\author{
Charles W. Fox · James D. Wagner • \\ Sara Cline $\cdot$ Frances Ann Thomas · \\ Frank J. Messina
}

Received: 6 September 2008/ Accepted: 12 November 2008/Published online: 28 November 2008

(C) Springer Science+Business Media B.V. 2008

\begin{abstract}
Independent populations subjected to similar environments often exhibit convergent evolution. An unresolved question is the frequency with which such convergence reflects parallel genetic mechanisms. We examined the convergent evolution of egg-laying behavior in the seed-feeding beetle Callosobruchus maculatus. Females avoid ovipositing on seeds bearing conspecific eggs, but the degree of host discrimination varies among geographic populations. In a previous experiment, replicate lines switched from a small host to a large one evolved reduced discrimination after 40 generations. We used line crosses to determine the genetic architecture underlying this rapid response. The most parsimonious genetic models included dominance and/or epistasis for all crosses. The genetic architecture underlying reduced discrimination in two lines was not significantly different from the architecture underlying differences between geographic populations, but the architecture underlying the divergence of a third line differed from all others. We conclude that convergence of this complex trait may in some cases involve parallel genetic mechanisms.
\end{abstract}

Keywords Callosobruchus · Dominance · Epistasis · Host shift · Hybrid · Line cross · Oviposition preference

C. W. Fox $(\bowtie) \cdot$ J. D. Wagner · S. Cline · F. A. Thomas Department of Entomology, S-225 Agricultural Science Center North, University of Kentucky, Lexington, KY 40546-0091, USA

e-mail: cfox@uky.edu; fox@uky.edu

J. D. Wagner $\cdot$ S. Cline $\cdot$ F. A. Thomas

Biology Program, Transylvania University, 300 N. Broadway, Lexington, KY 40508-1797, USA

F. J. Messina

Department of Biology, Utah State University, 5305 Old Main Hill, Logan, UT 84322, USA

\section{Introduction}

When selection varies over space and gene flow is sufficiently low, populations may exhibit local adaptation (Kawecki and Ebert 2004). Some cases of local adaptation have been used to support the idea that evolution can be predictable; independent populations subjected to similar environments often converge toward similar fitness-related traits (Hoekstra et al. 2006; Losos et al. 1998; Protas et al. 2006; but see Bieri and Kawecki 2003). An unresolved question is the frequency with which such convergence reflects parallel genetic mechanisms (Arendt and Reznick 2008; Wood et al. 2005; Zhang and Kumar 1997). For traits strongly influenced by one or a few genes, convergence may require little genetic modification, and homoplasy could arise from similar or even identical sequence-level changes (Colosimo et al. 2005; Odeen and Hastad 2003; Yokoyama et al. 2000). Many ecologically important traits are influenced by multiple loci, however, and their evolution will depend on covariances with other fitness components as well as genotype-by-environment interactions (Forister et al. 2007; Mackay and Anholt 2007). For these traits, there may be multiple genetic and developmental pathways by which different populations respond to similar challenges (Hoekstra and Nachman 2003; Stern and Orgogozo 2008).

Experimental evolution studies have provided some of the best evidence of the genetic basis of convergent evolution within species (Matos et al. 2004; Teotónio et al. 2004). For example, shifting replicate microbial populations to novel environments can produce repeatable modification of traits, through either similar or distinct genetic changes (Cooper et al. 2003; Travisano et al. 1995; Wichman et al. 1999). Less is known about the degree of parallelism underlying the convergence of complex, 
polygenic characters, such as behaviors (Bult and Lynch 1996). If independent lines subjected to quasi-natural selection (Fry 2003) converge on similar behavioral phenotypes, crossing experiments can determine whether parallel genetic changes mediated adaptation to the new environment. Line crosses also reveal the relative contributions of additivity, dominance, and epistasis in the divergence of lines occupying ancestral and novel environments (Rego et al. 2007; Tucić and Šešlija 2007).

In this study, we used line-cross analysis to examine the genetic architecture underlying convergent evolution of egg-laying behavior in the seed beetle Callosobruchus maculatus (F.) (Coleoptera: Chrysomelidae: Bruchinae). By detecting and avoiding seeds that already bear eggs, ovipositing females of $C$. maculatus produce non-random, uniform distributions of eggs among seeds, and reduce the severity of competition experienced by larval offspring (Messina and Renwick 1985). This behavior, often referred to as host discrimination, has evolved many times among insects whose larvae develop in small, discrete hosts (Nufio and Papaj 2001). The level of host discrimination varies among populations of C. maculatus (Messina 1989; Messina and Mitchell 1989), possibly because of concomitant variation in the sizes of host seeds and the competitiveness of co-occurring larvae (Messina 1991; Smith and Lessells 1985; Tuda and Iwasa 1998). Replicate lines of an Asian beetle population switched from a small host [mung bean, Vigna radiata (L.) Wilczek] to a large one [cowpea, $V$. unguiculata (L.) Walp] for $>40$ generations evolved increased acceptance of occupied seeds and reduced the uniformity of egg distributions (Messina and Karren 2003). By crossing each line switched to the novel host with a line kept on the ancestral host, we examined the parallelism of genetic architecture underlying the evolution of reduced host discrimination. We also crossed the mung-bean adapted Asian population with a cowpea-adapted African population that displays poor host discrimination (Messina and Karren 2003). We could thus compare the genetic architecture underlying an experimentally induced divergence with the architecture underlying differences between geographic populations (Fox et al. 2004b).

\section{Materials and methods}

\section{Beetle populations and hosts}

The Asian population was established from infested mung beans in southern India (henceforth, SI; Mitchell 1991). The African population was derived from cowpea seeds in Ouagadougou, Burkina Faso (henceforth, BF; Messina 1993). Both populations had been maintained in the laboratory on their ancestral hosts for $>100$ generations prior to the original selection experiment, and were thus likely to have reached genetic equilibrium with respect to the laboratory environment (Harshman and Hoffmann 2000). Laboratory conditions provide a reasonably close approximation of the 'natural' environment of C. maculatus, which has infested human stores of grain legumes for thousands of years and displays specific traits for exploiting grain-legume seeds both in the field and in storage (Tuda et al. 2006).

The original selection experiment is described in Messina and Karren (2003) and Messina (2004a). Two generations before the start of the experiment, the SI stock population was expanded by placing $>1,500$ adults into each of four jars containing $\approx 750 \mathrm{~g}$ of uninfested mung beans. Emerging adults were then used to establish six independent lines with $>2,000$ newly emerged adults per line. Three lines were maintained on the ancestral, mung bean host (SI-mung), and three were switched to cowpea (designated SI-cowpea replicates A, B and C). Subsequent generations were formed by adding 1,500-2,500 adults to $\approx 750 \mathrm{~g}$ of seeds (about 12,500 mung beans or 3,500 cowpeas). We maintained stock cultures and conducted the selection experiment in a growth chamber at $24 \pm 1^{\circ} \mathrm{C}$ and constant light. Assays of host discrimination behavior were conducted after 42-54 generations; each demonstrated divergence of the mung and cowpea lines (Messina and Karren 2003). The crosses described below were conducted after lines had been maintained on their respective hosts for 116 generations.

Line cross experimental design

At generation 117, we performed four types of crosses. One set of crosses, between the SI-mung and BF populations, was used to quantify the genetic architecture underlying differences between geographic populations adapted to different hosts (Fox et al. 2004b). The second set, between each of the three SI-cowpea lines and the SI-mung line, employed the same design, and was performed simultaneously in the same growth chamber. For simplicity, we present experimental details only for the crosses between generalized $\mathrm{P}_{1}$ and $\mathrm{P}_{2}$ lines; the actual crosses were SI-mung $\times$ BF, SI-mung $\times$ SI-cowpea replicate A, SI-mung $\times$ SI-cowpea replicate $B$, and SI-mung $\times$ SI-cowpea replicate C).

$\mathrm{P}_{1}$ and $\mathrm{P}_{2}$ beetles were mated to produce $\mathrm{F}_{1}, \mathrm{~F}_{2}$ and backcross progeny. Crosses were created over three generations so that all beetles could be scored simultaneously in the final generation (Fox et al. 2004a, b). The first generation consisted of only purebred parental beetles $\left(\mathrm{P}_{1}\right.$ and $\left.\mathrm{P}_{2}\right)$. For the second generation, emerging females 
were either mated with a male from the same line, or were mated with a male from the other line to create $F_{1}$ hybrids. All crosses were performed reciprocally as diagrammed in Bieri and Kawecki (2003). Thus, $F_{1}$ offspring were obtained from both $\mathrm{P}_{1} q \times \mathrm{P}_{2} \hat{\sigma}$ and $\mathrm{P}_{2} q \times \mathrm{P}_{1} \hat{o}$ crosses $\left(=F_{1}\right.$ and $F_{1 R}$, respectively). For generation three, we created 14 crosses: two purebreds, two $F_{1}$ crosses $\left(F_{1}\right.$ and $\left.F_{1 R}\right)$, two $F_{2}$ crosses $\left(F_{1} \propto \times F_{1} \hat{\jmath}, F_{1 R}+\times F_{1 R} \hat{\jmath}\right)$, four P1 backcrosses $\left(\mathrm{P}_{1} q \times \mathrm{F}_{1} \hat{\jmath}, \mathrm{P}_{1} q \times \mathrm{F}_{1 \mathrm{R}} \hat{\jmath}, \mathrm{F}_{1} q \times \mathrm{P}_{1} \hat{\jmath}, \mathrm{F}_{1 \mathrm{R}}\right.$

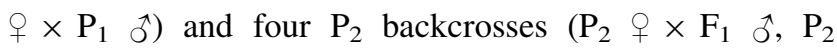
$\left.q \times \mathrm{F}_{1 \mathrm{R}} \hat{\jmath}, \mathrm{F}_{1} \uparrow \times \mathrm{P}_{2} \hat{\jmath}, \mathrm{F}_{1 \mathrm{R}}+\times \mathrm{P}_{2} \hat{\jmath}\right)$. Reciprocal crosses allowed us to test for maternal-genetic, Y-chromosome, and cytoplasmic effects on line-cross means.

We established a minimum of 10 mating pairs for each of the 14 crosses within each of the four cross types. Because cytoplasmic and Y-chromosome effects were not significant in any type of cross, we pooled reciprocal crosses that differed only in these effects. This reduced the number of crosses from 14 to 9 , and yielded a minimum of 25 pairs per cross (the mean number was 61 pairs). Matings were performed in $35-\mathrm{mm}$ Petri dishes containing $\approx 35$ mung bean seeds, with one mated pair per dish (isolated from all other pairs). Females were allowed to mate and oviposit for $48 \mathrm{~h}$, after which the parents were discarded. Seeds bearing a single egg were isolated in $35 \mathrm{~m}$ Petri dishes (one egg per dish) and reared to adult. Thus, all offspring larvae developed without competition, and emerging adults were unmated and of known parents. All offspring developed at $25^{\circ} \mathrm{C}$ and 15:9 light:dark in a single growth chamber. We used mung bean as the rearing host because larval survivorship is high on this host for both the SI and BF populations (Stillwell et al. 2007). The positions of dishes in the chamber were rotated daily. Prior to emergence, two offspring per family were randomly designated for estimating egg dispersion.

Egg dispersion among parental and hybrid females

Egg dispersion was measured in 60-mm Petri dishes containing 30 cowpea seeds. Each unmated female was collected within $24 \mathrm{~h}$ of adult emergence, and was paired with a random non-sibling male from the same cross type. This design does not allow us to disentangle male from female effects on oviposition behavior, but we had no a priori reason to expect a significant effect of the source of the male (Messina 1989; Messina and Slade 1997). Females were allowed to oviposit for $\sim 24 \mathrm{~h}$.

Each female's distribution of eggs was scored using the uniformity index $(U)$ of Messina and Mitchell (1989). This index depends on a female's frequency of "mistakes," which is defined as the number of eggs that would need to be transferred among seeds to convert the observed distribution to most uniform distribution possible (for a given number of eggs on 30 seeds). This observed number of mistakes is then compared to the expected number of mistakes committed by a hypothetical female that laid eggs randomly, i.e., according to a Poisson distribution. $U=$ (expected mistakes-observed mistakes)/expected mistakes. The index usually ranges between 0 and 1 , where 0 represents a random distribution and 1 represents a completely uniform one. $U$ will be $<0$ if a female tends to aggregate eggs among seeds. Because random and uniform distributions become indistinguishable when mean egg number is low (the sampling variance in $U$ increases with decreasing fecundity), we included in the analyses only females that laid $>10$ eggs. $U$ scores were obtained for either one or two females per family. When two females were used per family, scores were averaged to control for the non-independence of sisters. $U$ scores were obtained for a total 2,715 females, which were nearly evenly divided across cross types.

\section{Genetic analysis}

Composite genetic effects on line means were estimated as in Lynch and Walsh (1998). We used the genetic model of Kearsey and Pooni (1996), which has the parameterization described in Table 1 and uses the expected mean of $\mathrm{F}_{\infty}$ offspring as a point of reference. The parameterization of this model differs only slightly from that described by Lynch and Walsh (1998), who use expected phenotype of $\mathrm{F}_{2}$ offspring as a point of reference. The two models can be easily translated to alternate parameterizations (Basford and De Lacy 1979).

We tested goodness of fit to genetic models using the weighted residual sums of squares (Bradshaw and Holzapfel 2000). The weighted residual sums of squares is

$$
\mathrm{RSS}_{w}=\sum_{i=1}^{k} \frac{\mathrm{e}_{i}^{2}}{\mathrm{SE}_{i}^{2}}
$$

where $k$ is the number of crosses, $\mathrm{e}_{i}^{2}$ is the difference between the observed and predicted composite genetic effects, and $\mathrm{SE}_{i}^{2}$ are the standard errors of the estimated composite genetic effects (Bieri and Kawecki 2003; Lynch and Walsh 1998). For normally distributed data $\mathrm{RSS}_{w}$ is $\chi^{2}$ distributed with degrees of freedom equal to the number of lines minus the number of parameters in the model. A significant $\chi^{2}$ indicates that the fitted model was inadequate to explain the observed line cross means. Because we are interested in eight different parameters [additive $(\alpha)$, dominance $(\delta)$, additive $\times$ additive epistasis $\left(\alpha^{2}\right)$, additive $\times$ dominance epistasis $(\alpha \delta)$, dominance $\times$ dominance epistasis $\left(\delta^{2}\right)$, an additive genetic maternal effect $\left(m_{\alpha}\right)$, a dominance genetic maternal effect $\left(m_{\delta}\right)$, and a cytoplasmic effect $(c)]$ there are $2^{8}$ or 256 possible models. Traditional 
Table 1 The parameter coefficients used for calculating composite genetic effects

\begin{tabular}{|c|c|c|c|c|c|c|c|c|c|c|c|}
\hline Cross label & Parents of cross & $\mu_{0}$ & $\alpha$ & $\delta$ & $\alpha^{2}$ & $\alpha \delta$ & $\delta^{2}$ & $m_{\alpha}$ & $m_{\delta}$ & $c$ & $Y$ \\
\hline $\mathrm{P}_{1}$ & $\mathrm{P}_{1} \times \mathrm{P}_{1}$ & 1 & 1 & 0 & 1 & 0 & 0 & 1 & 0 & 1 & 1 \\
\hline $\mathrm{P}_{2}$ & $\mathrm{P}_{2} \times \mathrm{P}_{2}$ & 1 & -1 & 0 & 1 & 0 & 0 & -1 & 0 & -1 & -1 \\
\hline $\mathrm{F}_{1}$ & $\mathrm{P}_{1} \times \mathrm{P}_{2}$ & 1 & 0 & 1 & 0 & 0 & 1 & 1 & 0 & 1 & -1 \\
\hline $\mathrm{F}_{1} \mathrm{R}$ & $\mathrm{P}_{2} \times \mathrm{P}_{1}$ & 1 & 0 & 1 & 0 & 0 & 1 & -1 & 0 & -1 & 1 \\
\hline $\mathrm{F}_{2}$ & $\left(\mathrm{P}_{1} \times \mathrm{P}_{2}\right) \times\left(\mathrm{P}_{1} \times \mathrm{P}_{2}\right)$ & 1 & 0 & 0.5 & 0 & 0 & 0.25 & 0 & 1 & 1 & -1 \\
\hline $\mathrm{F}_{2} \mathrm{R}$ & $\left(\mathrm{P}_{2} \times \mathrm{P}_{1}\right) \times\left(\mathrm{P}_{2} \times \mathrm{P}_{1}\right)$ & 1 & 0 & 0.5 & 0 & 0 & 0.25 & 0 & 1 & -1 & 1 \\
\hline $\mathrm{B}_{1} \mathrm{a}$ & $\mathrm{P}_{1} \times\left(\mathrm{P}_{1} \times \mathrm{P}_{2}\right)$ & 1 & 0.5 & 0.5 & 0.25 & 0.25 & 0.25 & 1 & 0 & 1 & -1 \\
\hline $\mathrm{B}_{1} \mathrm{~b}$ & $\mathrm{P}_{1} \times\left(\mathrm{P}_{2} \times \mathrm{P}_{1}\right)$ & 1 & 0.5 & 0.5 & 0.25 & 0.25 & 0.25 & 1 & 0 & 1 & 1 \\
\hline $\mathrm{B}_{1} \mathrm{Ra}$ & $\left(\mathrm{P}_{1} \times \mathrm{P}_{2}\right) \times \mathrm{P}_{1}$ & 1 & 0.5 & 0.5 & 0.25 & 0.25 & 0.25 & 0 & 1 & 1 & 1 \\
\hline $\mathrm{B}_{1} \mathrm{Rb}$ & $\left(\mathrm{P}_{2} \times \mathrm{P}_{1}\right) \times \mathrm{P}_{1}$ & 1 & 0.5 & 0.5 & 0.25 & 0.25 & 0.25 & 0 & 1 & -1 & 1 \\
\hline $\mathrm{B}_{2} \mathrm{a}$ & $\mathrm{P}_{2} \times\left(\mathrm{P}_{1} \times \mathrm{P}_{2}\right)$ & 1 & -0.5 & 0.5 & 0.25 & -0.25 & 0.25 & -1 & 0 & -1 & -1 \\
\hline $\mathrm{B}_{2} \mathrm{~b}$ & $\mathrm{P}_{2} \times\left(\mathrm{P}_{2} \times \mathrm{P}_{1}\right)$ & 1 & -0.5 & 0.5 & 0.25 & -0.25 & 0.25 & -1 & 0 & -1 & 1 \\
\hline $\mathrm{B}_{2} \mathrm{Ra}$ & $\left(\mathrm{P}_{1} \times \mathrm{P}_{2}\right) \times \mathrm{P}_{2}$ & 1 & -0.5 & 0.5 & 0.25 & -0.25 & 0.25 & 0 & 1 & 1 & -1 \\
\hline $\mathrm{B}_{2} \mathrm{Rb}$ & $\left(\mathrm{P}_{2} \times \mathrm{P}_{1}\right) \times \mathrm{P}_{2}$ & 1 & -0.5 & 0.5 & 0.25 & -0.25 & 0.25 & 0 & 1 & -1 & -1 \\
\hline
\end{tabular}

$\mu_{0}$, mean; $\alpha$, additive; $\delta$, dominance; $\alpha^{2}$, additive-additive epistasis; $\alpha \delta$, additive-dominance epistasis; $\delta^{2}$, dominance-dominance epistasis; $\mathrm{m}_{\alpha}$, additive-genetic maternal; $\mathrm{m}_{\delta}$, dominance genetic maternal; c, cytoplasmic; $\mathrm{Y}$, y chromosome. Table modified from (Gilchrist and Partridge 1999)

joint-scaling techniques avoid the need to compare all models by adding parameters sequentially, starting with additivity, then adding dominance, then epistasis, etc., until line means predicted by the model no longer differ from the observed means (based on the comparison of $\mathrm{RSS}_{w}$ to a $\chi^{2}$ distribution, as described above) (Bradshaw and Holzapfel 2000; Mather and Jinks 1982). However, the order in which terms are introduced into the model affects the ability to detect effects added later and this technique does not always produce the most parsimonious model. We used Akaike's information criterion to find the most parsimonious model (following Bieri and Kawecki 2003; see Burnham and Anderson 1998, 2004). This technique chooses a model that is the best compromise between the amount of variance explained and the number of parameters in the model. The model with the lowest AIC is most parsimonious, where AIC $=-2 \ln (L)+2 K$, where $L$ is the $\log$-likelihood of the model given the data and $K$ is the number of parameters fitted in the model. Bieri and Kawecki (2003) showed that AIC $=\mathrm{RSS}_{w}+2 K+$ constant. The constant is the same for all models and thus need not be calculated to compare different genetic models.

Because the number of possible models is large, we first reduced the number of candidate models. Y-chromosome and cytoplasmic effects were not significant, so were dropped from subsequent analyses. This allowed us to reduce the means of the 14 crosses to 9 means by pooling the two $F_{2}$ crosses $\left(F_{1}+\times F_{1} \hat{\jmath}, F_{1 R}+\times F_{1 R} \hat{\jmath}\right)$ into a single $\mathrm{F}_{2}, \mathrm{P}_{1}+\times \mathrm{F}_{1}$ ô and $\mathrm{P}_{1}+\times \mathrm{F}_{1 \mathrm{R}}$ ô into $\mathrm{B}_{1}, \mathrm{~F}_{1}$ $q \times \mathrm{P}_{1}$ ô and $\mathrm{F}_{1 \mathrm{R}}+\times \mathrm{P}_{1}$ o into $\mathrm{B}_{1 \mathrm{R}}, \mathrm{P}_{2}+\times \mathrm{F}_{1}$ ô and $\mathrm{P}_{2}$ $q \times \mathrm{F}_{1 \mathrm{R}}$ ô into $\mathrm{B}_{2}$ and $\mathrm{F}_{1} q \times \mathrm{P}_{2} \hat{\jmath}$ and $\mathrm{F}_{1 \mathrm{R}} q \times \mathrm{P}_{2}$ ô into
$\mathrm{B}_{2 \mathrm{R}}$ (Table 1). To further reduce the number of candidate models, we pooled the three forms of digenic epistasis and compared eight models for each trait (following Bieri and Kawecki 2003): a model with only the overall mean $\left(\mu_{0}\right)$, an additive model $\left(\mu_{0}+\alpha\right)$, a dominance model $\left(\mu_{0}+\delta\right)$, an epistasis model $\left(\mu_{0}+\alpha^{2}+\alpha \delta+\delta^{2}\right)$, an additivedominance model $\left(\mu_{0}+\alpha+\delta\right)$, an additive-epistasis model $\left(\mu_{0}+\alpha+\alpha^{2}+\alpha \delta+\delta^{2}\right)$, a dominance-epistasis model $\left(\mu_{0}+\delta+\alpha^{2}+\alpha \delta+\delta^{2}\right)$ and an additive-dominance-epistasis model $\left(\mu_{0}+\alpha+\delta+\alpha^{2}+\alpha \delta+\delta^{2}\right)$. We chose the model with the lowest AIC as most parsimonious. A difference in AIC of $<2$ between a reduced and expanded model $\left(\Delta_{\text {AIC }}\right)$ is considered weak support that the additional term(s) significantly improves the fit of the model (Burnham and Anderson 2004). Thus, when two models differed in AIC by $<2$, the reduced model was considered most parsimonious. Only if the most parsimonious model included epistasis did we expand our model into all possible models including the three forms of digenic epistasis. For example, if the additive-epistasis model was most parsimonious, we expanded this into the following seven models, $\mu_{0}+\alpha+\alpha^{2}, \quad \mu_{0}+\alpha+\alpha \delta$, $\mu_{0}+\alpha+\delta^{2}, \quad \mu_{0}+\alpha+\alpha^{2}+\alpha \delta, \quad \mu_{0}+\alpha+\alpha^{2}+\delta^{2}$, $\mu_{0}+\alpha+\alpha \delta+\delta^{2}$, and $\mu_{0}+\alpha+\alpha^{2}+\alpha \delta+\delta^{2}$, and again chose the model with the lowest AIC as our most parsimonious.

It is possible that the most parsimonious model includes parameters that contribute little, such that removing the parameter would not significantly decrease the fit of the model. We used a likelihood-ratio test to determine whether the removal of individual terms significantly reduced 
the fit of the model (Lynch and Walsh 1998). The degree of reduced fit of the model is estimated as $\Lambda=\mathrm{RSS}_{w \text { (reduced }}$ model) $-\mathrm{RSS}_{w \text { (full model) }}$. The parameter $\Lambda$ is $\chi^{2}$-distributed at large sample sizes, with degrees of freedom equal to the difference in the number of parameters in the two models.

A primary goal of this study was to compare composite genetic effects among the different types of crosses, i.e., to establish whether the genetic architecture underlying line differences was itself similar among cross types. To do this, we fit a common model to each type of cross (a model including all effects significant in either cross) and then compared the estimated composite genetic effects using a Wald Chi-square test, where $\chi^{2}=\left(b_{1}-b_{2}\right)^{2} /\left[\operatorname{SE}\left(b_{1}\right)^{2}+-\right.$ $\left.\mathrm{SE}\left(b_{2}\right)^{2}\right]$, where $b_{1}$ and $b_{2}$ are the composite genetic effects in each environment and $\operatorname{SE}\left(b_{1}\right)$ and $\operatorname{SE}\left(b_{2}\right)$ are the standard errors of those composite genetic effects (Allison 1995; Fox et al. 2004a, b). The sum of the Wald $\chi^{2}$ provides a test of whether two models are different; the sum is $\chi^{2}$ distributed with $K$ degrees of freedom, where $K$ is the number of parameters in the model (not the sum of the number of parameters in the two models being compared). Because parameter estimates are sensitive to which parameters are included in the model, we compared models with the same parameterization. For example, if a parameter was significantly different from zero in only one of the two models to be compared, it was nonetheless included in both models for the purpose of hypothesis testing. The line difference in $\mu_{0}$ was not included in this analysis. However, the difference in $U$ between the two parental populations in a cross does affect estimates of the composite genetic effects and thus affects the hypothesis tests. We corrected for differences in $U$ between lines by dividing the composite genetic effects and their standard errors by the difference between the two parental lines, before calculating $\chi^{2}$, so that the composite effects were a proportion of the difference between the two parental lines in the cross. This difference was 0.408 for the SI-mung $\times$ BF cross, and $0.354,0.341$, and 0.294 for replicates A, B and C, (respectively) of the SI-mung $\times$ SI-cowpea crosses.

\section{Results}

\section{Population differences}

We first compared egg distributions produced by females from lines that had spent 116 generations on cowpea (SIcowpea) with those produced by females from lines maintained on mung bean (SI-mung). As expected from the earlier results, SI-cowpea females laid eggs much less uniformly than did SI-mung females (Fig. $1 ; F_{1,4}=174$, $P<0.001)$. Mean $U$ scores of SI-cowpea females converged toward those of $\mathrm{BF}$ females (whose ancestral host is cowpea), but the former group still produced slightly more uniform distributions $\left(F_{1,4}=14.1, P=0.02\right)$. We found no significant variation among replicate lines within any of the three populations $(F<1.52, P>0.22$ for each population).

Genetic architecture of population differences

The three SI-cowpea lines were independently evolving populations, and thus they represent true replicates of potential differentiation from the ancestral population. However, the three replicates of the SI-mung and BF populations were arbitrarily defined when we initiated the line crosses because a defined set of beetles needed to be crossed to each of the three SI-cowpea lines. We thus pooled the three SI-mung and BF lines in Fig. 1 for assessing the inheritance of behavioral differences between SI-mung and BF.

The AIC most parsimonious model for the genetic difference between the SI-mung population and the $\mathrm{BF}$ population included only the composite genetic effects of overall mean $\left(\mu_{0}\right)$, additive $(\alpha)$, dominance $(\delta)$, and additive $\times$ additive epistasis $\left(\alpha^{2}\right)$ (Fig. 2a; Table 2). Deletion of either dominance or additive $x$ additive epistasis terms from the model significantly reduced the fit to the data $\left(\chi_{1}^{2}=6.65, P=0.01\right.$, and $\chi_{1}^{2}=6.71, P=0.01$, respectively). These results are largely consistent with previous crosses that examined differences between these populations; significant dominance $(\delta)$ was detected in all previous crosses, and additive $\times$ additive epistasis $\left(\alpha^{2}\right)$ was detected in two of four previous crosses (Fox et al. 2004a).

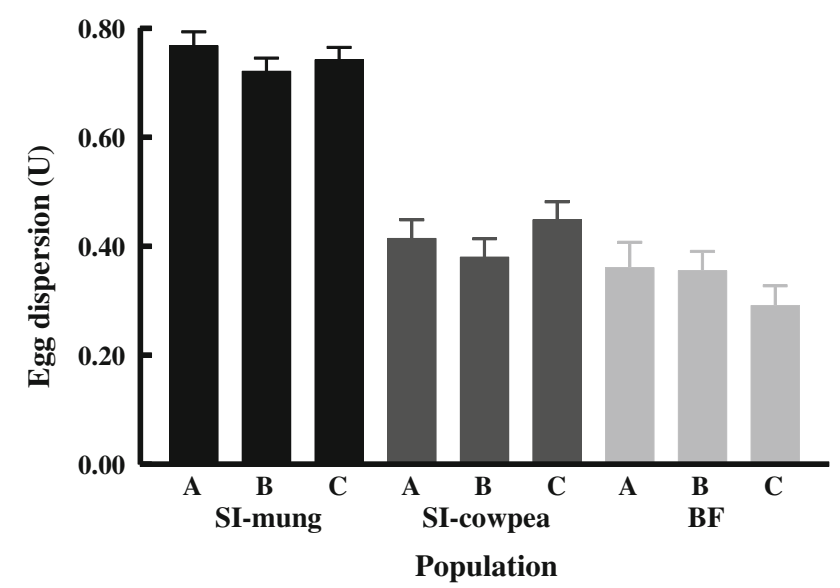

Fig. 1 Mean egg dispersion scores $(U+\mathrm{SE})$ of females in lines of the SI-mung, SI-cowpea, and BF populations (see text). SI-mung represents SI lines maintained on the ancestral host, whereas SIcowpea represents SI lines switched from the ancestral host to a new host (cowpea) 116 generations prior to this study. Cowpea is the ancestral host of the BF lines. A $U$ score of 1 signifies a completely uniform dispersion; 0 signifies a random (Poisson) distribution 
Dominance similarly contributed to the genetic differentiation of the SI-cowpea lines from the SI-mung population; dominance was present in two of the three AIC best fit models (in crosses involving SI-cowpea replicates $\mathrm{B}$ and $\mathrm{C}$ ). Formal comparisons indicated that genetic architectures underlying differences in egg dispersion were similar, but not identical, among the three types of crosses. The genetic architecture underlying the difference between SI-cowpea line B and SI-mung did not differ from the architecture underlying the divergence of SI-cowpea line C and SI-mung $\left(\chi_{2}^{2}=1.0, P=0.59\right)$. However, the genetic architecture that accounted for the divergence between SI-cowpea line A and SI-mung differed from the architecture underlying the divergence of SI-cowpea line $\mathrm{C}$ and SI-mung $\left(\chi_{3}^{2}=8.0, P=0.046\right)$, and the difference between the architecture underlying this cross and the genetic architecture that accounted for the divergence of the SI-cowpea line B and SI-mung approached significance $\left(\chi_{3}^{2}=6.2, P=0.10\right)$. In both cases, the effect of dominance was significant in crosses involving SI-cowpea lines B and $\mathrm{C}$, but not in the cross involving line $\mathrm{A}$. That dominance did not contribute to the line differences in crosses involving line A was further indicated by two observations: (1) adding dominance to the AIC best fit model $\left(\mu_{0}+\alpha+\delta \delta\right)$ did not significantly improve the fit of the model, and (2) adding dominance to the strictly additive model $\left(\mu_{0}+\alpha\right)$ did not improve the fit of the model (this is equivalent to adding dominance instead of $\delta \delta$ epistasis to the reduced model; replacing $\delta \delta$ epistasis with dominance significantly reduced the fit of the model to the data relative to the AIC best fit model in Table 2). Epistasis was also significant in the cross involving line $\mathrm{A}$, but not in crosses involving lines $\mathrm{B}$ and $\mathrm{C}$.
The above comparisons provided mixed results with respect to whether decreased host discrimination in the three cowpea lines occurred via similar genetic mechanisms. A second way to look for genetic parallelism is to formally compare the genetic architecture underlying differences between the SI-mung and cowpea lines with the architecture underlying the difference between the SImung and BF lines. Differences between the SI-mung and cowpea lines were produced by laboratory selection, whereas the SI-mung and BF lines are derived from geographically distant populations on different hosts. For SIcowpea lines B and C, the genetic architecture estimated from the SI-cowpea $\times$ SI-mung crosses did not differ from the estimated genetic architecture underlying the SImung $\times \mathrm{BF}$ cross $\left(\chi_{3}^{2}<0.73, P>0.86\right)$. However, the estimated genetic architecture of the cross between SImung and SI-cowpea line A differed significantly from the architecture underlying the SI-mung $\times \mathrm{BF}$ cross $\left(\chi_{3}^{2}=12.6, P=0.006\right)$; the latter cross was characterized by greater effects of dominance $\left(\chi_{1}^{2}=3.5, P=0.06\right)$ and epistasis $\left(\chi_{1}^{2}=12.6, P<0.001\right)$. In contrast, the relative effects of dominance and epistasis did not differ significantly when the other two crosses $($ SI-mung $\times$ SI-cowpea lines $\mathrm{B}$ or $\mathrm{C}$ ) were compared to the SI-mung $\times \mathrm{BF}$ cross $\left(\chi_{1}^{2}<0.30, P>0.58\right)$ after fitting a common model.

\section{Discussion}

When three lines were switched from the small mung-bean host to the large cowpea host and allowed to adapt to this new host for 116 generations, each evolved a similar
Fig. 2 Mean egg dispersion scores $(U \pm \mathrm{SE})$ of parental and hybrid females according to in the proportion of genes from the SI-mung line. Separate crosses were performed between the SImung line and each of three replicate SI-cowpea lines. A $U$ score of 1 signifies a completely uniform dispersion; 0 signifies a random (Poisson) distribution
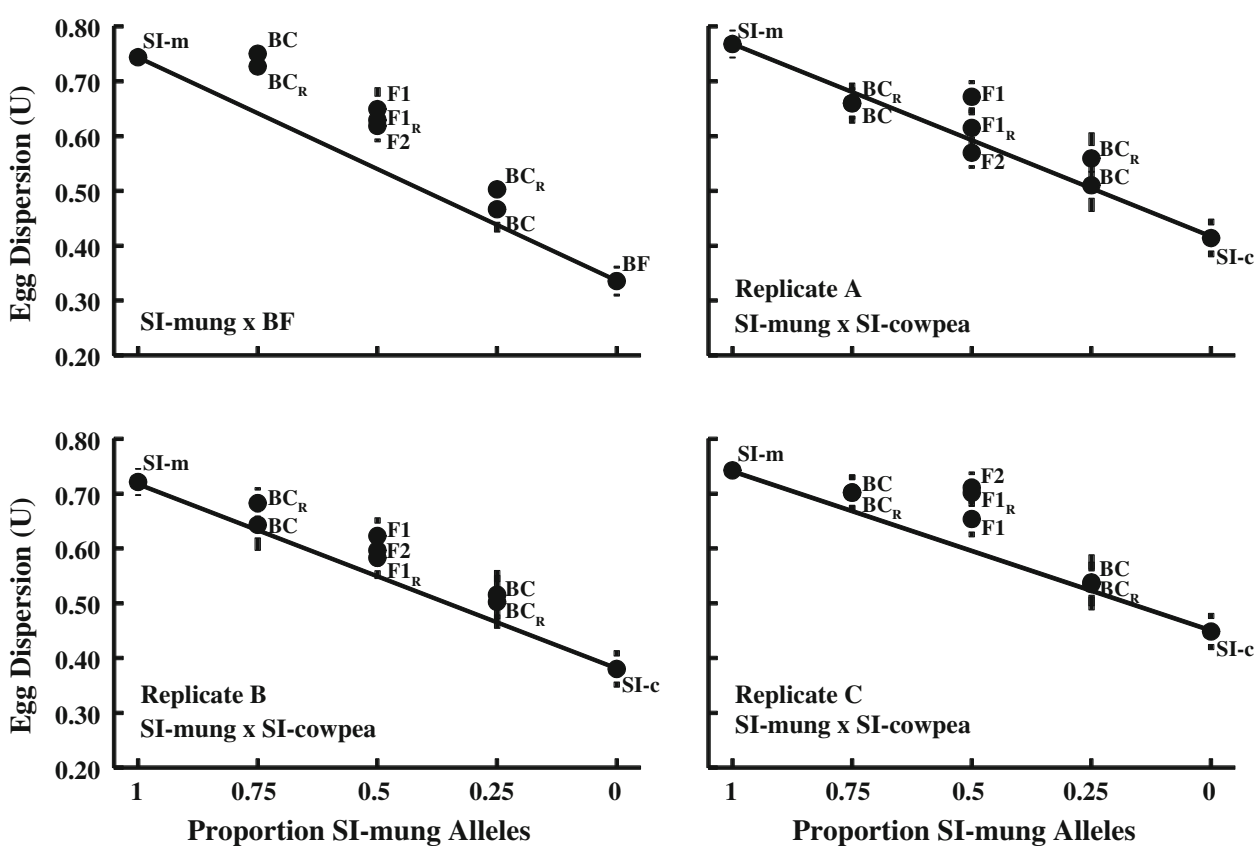
Table 2 Most parsimonious models and composite genetic effects contributing to differences in egg dispersion ( $U$ scores) between Callosobruchus maculatus populations

\begin{tabular}{lllll}
\hline Egg dispersion & SI-mung $\times$ BF & SI-mung $\times$ SI-cowpea A & SI-mung $\times$ SI-cowpea B & SI-mung $\times$ SI-cowpea C \\
\hline$\mu_{0}$ & $0.629 \pm 0.033$ & $0.579 \pm 0.016$ & $0.557 \pm 0.018$ & $0.599 \pm 0.018$ \\
$\alpha$ & $0.218 \pm 0.009$ & $0.168 \pm 0.019$ & $0.168 \pm 0.018$ & $0.147 \pm 0.018$ \\
$\delta$ & $0.012 \pm 0.005$ & - & $0.057 \pm 0.032^{\mathrm{a}}$ & $0.089 \pm 0.028$ \\
$\alpha^{2}$ & $-0.091 \pm 0.036$ & - & - & - \\
$\alpha \delta$ & - & - & - & - \\
$\delta^{2}$ & - & $0.064 \pm 0.030$ & $1.62 \mathrm{NS}$ & - \\
$\chi^{2}$ & $4.78 \mathrm{NS}$ & $4.79 \mathrm{NS}$ & $8.65 \mathrm{NS}$ \\
\hline
\end{tabular}

SI-mung, the Asian population maintained on the ancestral host, mung bean; SI-cowpea (A-C), lines shifted to cowpea. BF, the African population maintained on cowpea

Model parameters: $\mu_{0}$, mean; $\alpha$, additive; $\delta$, dominance; $\alpha^{2}$, additive-additive epistasis; $\alpha \delta$, additive-dominance epistasis; $\delta^{2}$, dominancedominance epistasis; $\chi^{2}$, goodness of fit of the model to the real data-a low $\chi^{2}$ indicates a better fit

$\chi^{2}$ values are presented for the best fit model; NS indicates that the model adequately explains the data

a A parameter in the most parsimonious model whose deletion did not significantly reduce the fit of the model to the observed line means

reduction in the level of host discrimination (Fig. 1) (Messina and Karren 2003). Line-cross results reported here suggest that parallel genetic mechanisms were responsible for convergence of cowpea-adapted lines B and C toward less uniform egg-laying, but the evolution of lower host discrimination in cowpea line A involved additional or distinct genetic changes. Thus, even when lines subjected to quasi-natural selection are all recently derived from the same ancestral stock, convergent phenotypic evolution may be accomplished via different genetic mechanisms (reviews by Arendt and Reznick 2008; Wood et al. 2005).

All of our crosses indicated significant non-additive genetic effects underlying evolved differences in host discrimination. Non-additive genetic effects on animal behaviors are commonly detected in behavioral studies; indeed, an influence of dominance and/or epistasis on phenotypic variation in behavior appears to be the rule more than the exception (Mackay 2008; Meffert et al. 2002). However, few studies have quantified the relative contributions of different types of non-additivity, or have examined how the contribution of non-additivity varies among distinct evolutionary events. We detected non-additive genetic effects in all crosses, but the relative contributions of dominance and epistasis differed among crosses. Most crosses (all except the SI-mung A $\times$ SI-cowpea) exhibited dominance of higher host discrimination over reduced host discrimination. However, we did not detect any dominance deviation in the SI-mung $\mathrm{A} \times$ SI-cowpea cross. This cross also differed from the rest in being the only one for which $\delta^{2}$ epistasis was detected; no epistasis was detected in either of the crosses between SI-cowpea and the other two SI-mung lines.

The line crosses also revealed that the genetic architecture underlying the divergence of the ancestral mungadapted line from two of the cowpea lines (B and C) was not statistically different than the architecture underlying the naturally-evolved divergence of the mung-bean adapted population (SI population from Asia) and the cowpeaadapted population (BF population from Africa). Thus, three independent evolutionary divergences (two experimental and one natural), associated with differences in host use (mung vs. cowpea), exhibited similar underlying genetic architecture, whereas the genetic architecture underlying a fourth independent evolutionary divergence (SI-cowpea line A) differed. This variation suggests that the relative contributions of additivity, dominance and epistasis to population differences are somewhat predictable but not absolute; i.e., one particular genetic architecture was most likely to underlie adaptive evolution to an alternate host, but alternative genetic architectures can also underlie the evolution of egg dispersion. Whether parallel declines in host discrimination resulted from changes in few or many loci, they did not all arise from the same allelic substitutions.

Alternative paths of evolutionary change may be expected for animal behaviors, which are typically polygenic, composite traits (Price and Schluter 1991) that can be strongly influenced by non-additive genetic effects and genotype-by-environment interactions (Craig et al. 2001; Keese 1996; Meffert et al. 2002; Tucić and Šešlija 2007). In this study, how a female allocates her eggs among seeds was represented by a single $U$ score and treated as if it were a single trait, but host discrimination likely depends on several constituent traits, including (1) the composition of a female's marking pheromone (Credland and Wright 1990), (2) the amount of pheromone she deposits, (3) her sensitivity to pheromone presence on occupied seeds (Messina et al. 1991), and (4) her foraging habits, all of which determine the thoroughness by which she inspects potential hosts (Horng et al. 1999). Changes in any of these traits (or others) can mediate "sloppier" egg-laying. Identifying 
which traits are most responsible for the divergence of the cowpea and mung-bean lines could be pursued through systematic, continuous observations of foraging females from the SI-mung and cowpea lines, as well as through assays that compare female responses to occupied seeds that bear SI-mung or SI-cowpea eggs (Parr et al. 1996).

The Callosobruchus-legume association provides an excellent model system for examining the experimental evolution of a variety of behavioral, morphological, physiological, and life-history traits (Fricke and Arnqvist 2007; Messina and Karren 2003; Wasserman and Futuyma 1981). Laboratory populations appear to maintain selectable variation in most characters examined (Credland 1987; Kawecki 1995), and artificial or quasi-natural selection experiments can establish multiple lines that simultaneously adapt to the same novel challenges (Messina 2004a, b; Tuda and Iwasa 1998). In addition, geographic populations can be highly divergent for fitness-related characters (Messina and Mitchell 1989; Mitchell 1990), and line crosses can establish the genetic architecture of population differentiation (Bieri and Kawecki 2003; Fox et al. 2004a, b). Unfortunately, C. maculatus does not at present have a well-characterized genome. Unraveling this genome should produce abundant insights into the genetics of adaptation, and in particular the mechanisms and frequency of parallel evolution.

Acknowledgments This research was supported by grants from Kentucky EPSCoR (to CWF and JDW), the University of Kentucky Agricultural Experiment Station (to CWF), and the Utah Agricultural Experiment Station (to FJM; paper no. 8010).

\section{References}

Allison PD (1995) Survival analysis using the SAS system: a practical guide. SAS Institute, Inc., Cary

Arendt J, Reznick D (2008) Convergence and parallelism reconsidered: what have we learned about the genetics of adaptation? Trends Ecol Evol 23:26-32. doi:10.1016/j.tree.2007.09.011

Basford KE, De Lacy IH (1979) The use of matrix specifications in defining gene action in genotypic value models and generation mean analysis. Theor Appl Genet 55:225-229. doi:10.1007/ BF00268116

Bieri J, Kawecki TJ (2003) Genetic architecture of differences between populations of cowpea weevil (Callosobruchus maculatus) evolved in the same environment. Evol Int $\mathrm{J}$ Org Evol 57:274-287

Bradshaw WE, Holzapfel CM (2000) The evolution of genetic architecture and the divergence of natural populations. In: Wolf JB, Brodie EDI, Wade MJ (eds) Epistasis and the evolutionary process. Oxford University Press, New York

Bult A, Lynch CB (1996) Multiple selection responses in house mice bidirectionally selected for thermoregulatory nest-building behavior: crosses of replicate lines. Behav Genet 26:439-446. doi:10.1007/BF02359488

Burnham KP, Anderson DA (1998) Model selection and inference. Springer Mathematics, New York
Burnham KP, Anderson DA (2004) Multimodel inference: understanding AIC and BIC in model selection. Sociol Methods Res 33:261-304. doi:10.1177/0049124104268644

Colosimo PF, Hosemann KE, Balabhadra S, Villarreal G, Dickson M, Grimwood J, Schmutz J, Myers RM, Schluter D, Kingsley DM (2005) Widespread parallel evolution in sticklebacks by repeated fixation of ectodysplasin alleles. Science 307:1928-1933. doi: 10.1126/science.1107239

Cooper TF, Rozen DE, Lenski RE (2003) Parallel changes in qene expression after 20, 000 generations of evolution in Escherichia coli. Proc Natl Acad Sci USA 100:1072-1077. doi:10.1073/pnas. 0334340100

Craig TP, Horner JD, Itami JK (2001) Genetics, experience, and hostplant preference in Eurosta solidaginis: implications for host shifts and speciation. Evol Int J Org Evol 55:773-782. doi: 10.1554/0014-3820(2001)055[0773:GEAHPP]2.0.CO;2

Credland PF (1987) Effects of host change on the fecundity and development of an unusual strain of Callosobruchus maculatus (F) (Coleoptera: Bruchidae). J Stored Prod Res 23:91-98. doi: 10.1016/0022-474X(87)90022-1

Credland PF, Wright AW (1990) Oviposition deterrents of Callosobruchus maculatus (Coleoptera: Bruchidae). Physiol Entomol 15:285-298. doi:10.1111/j.1365-3032.1990.tb00517.x

Forister ML, Ehmer AG, Futuyma DJ (2007) The genetic architecture of a niche: variation and covariation in host use traits in the Colorado potato beetle. J Evol Biol 20:985-996. doi:10.1111/j. 1420-9101.2007.01310.x

Fox CW, Czesak ME, Wallin WG (2004a) Complex genetic architecture of population differences in adult lifespan of a beetle: nonadditive inheritance, gender differences, body size and a large maternal effect. J Evol Biol 17:1007-1017. doi: 10.1111/j.1420-9101.2004.00752.x

Fox CW, Stillwell RC, Amarillo AR, Czesak ME, Messina FJ (2004b) Genetic architecture of population differences in oviposition behaviour of the seed beetle Callosobruchus maculatus. J Evol Biol 17:1141-1151. doi:10.1111/j.1420-9101.2004.00719.x

Fricke C, Arnqvist G (2007) Rapid adaptation to a novel host in a seed beetle (Callosobruchus maculatus): the role of sexual selection. Evol Int J Org Evol 61:440-454. doi:10.1111/j. 1558-5646.2007.00038.x

Fry JD (2003) Detecting ecological trade-offs using selection experiments. Ecology 84:1672-1678. doi:10.1890/0012-9658 (2003)084[1672:DETUSE]2.0.CO;2

Gilchrist AS, Partridge L (1999) A comparison of the genetic basis of wing size divergence in three parallel body size clines of Drosophila melanogaster. Genetics 153:1775-1787

Harshman LG, Hoffmann AA (2000) Laboratory selection experiments using Drosophila: what do they really tell us? Trends Ecol Evol 15:32-36. doi:10.1016/S0169-5347(99)01756-5

Hoekstra HE, Nachman MW (2003) Different genes underlie adaptive melanism in different populations of rock pocket mice. Mol Ecol 12:1185-1194. doi:10.1046/j.1365-294X.2003.01788.x

Hoekstra HE, Hirschmann RJ, Bundey RA, Insel PA, Crossland JP (2006) A single amino acid mutation contributes to adaptive beach mouse color pattern. Science 313:101-104. doi: $10.1126 /$ science. 1126121

Horng SB, Lin HC, Wu WJ, Godfray HCJ (1999) Behavioral processes and egg-laying decisions of the bean weevil, Callosobruchus maculatus. Res Popul Ecol (Kyoto) 41:283-290

Kawecki TJ (1995) Expression of genetic and environmental variation for life-history characters on the usual and novel hosts in Callosobruchus maculatus (Coleoptera: Bruchidae). Heredity 75:70-76. doi:10.1038/hdy.1995.105

Kawecki TJ, Ebert D (2004) Conceptual issues in local adaptation. Ecol Lett 7:1225-1241. doi:10.1111/j.1461-0248.2004.00684.x 
Kearsey MJ, Pooni HS (1996) The genetical analysis of quantitative traits. Chapman \& Hall, London

Keese MC (1996) Feeding responses of hybrids and the inheritance of host-use traits in leaf feeding beetles (Coleoptera: Chrysomelidae). Heredity 76:36-42. doi:10.1038/hdy.1996.5

Losos JB, Jackman TR, Larson A, de Queiroz K, Rodriguez-Schettino L (1998) Contingency and determinism in replicated adaptive radiations of island lizards. Science 279:2115-2118. doi: 10.1126/science.279.5359.2115

Lynch M, Walsh B (1998) Genetics and analysis of quantitative traits. Sinauer Associates, Inc, Sunderland

Mackay TFC (2008) The genetic architecture of complex behaviors: lessons from Drosophila. Genetica. doi:10.1007/s10709-0089310-6

Mackay TFC, Anholt RRH (2007) Ain't misbehavin? Genotypeenvironment interactions and the genetics of behavior. Trends Genet 23:311-314. doi:10.1016/j.tig.2007.03.013

Mather K, Jinks JL (1982) Biometrical genetics, 3rd edn. Chapman \& hall, London

Matos M, Simoes P, Duarte A, Rego C, Avelar T, Rose MR (2004) Convergence to a novel environment: comparative method versus experimental evolution. Evol Int J Org Evol 58:15031510

Meffert LM, Hicks SK, Regan JL (2002) Nonadditive genetic effects in animal behavior. Am Nat 160:S198-S213. doi:10.1086/ 342896

Messina FJ (1989) Genetic basis of variable oviposition behavior in Callosobruchus maculatus (Coleoptera: Bruchidae). Ann Entomol Soc Am 82:792-796

Messina FJ (1991) Life history variation in a seed beetle: adult egglaying vs larval competitive ability. Oecologia 85:447-455. doi: 10.1007/BF00320624

Messina FJ (1993) Heritability and 'evolvability' of fitness components in Callosobruchus maculatus. Heredity 71:623-629. doi: 10.1038/hdy.1993.187

Messina FJ (2004a) How labile are the egg-laying preferences of seed beetles? Ecol Entomol 29:318-326. doi:10.1111/j.1365-2311. 2004.0599.x

Messina FJ (2004b) Predictable modification of body size and competitive ability following a host shift by a seed beetle. Evol Int J Org Evol 58:2788-2797

Messina FJ, Karren ME (2003) Adaptation to a novel host modifies host discrimination by the seed beetle Callosobruchus maculatus. Anim Behav 65:501-507. doi:10.1006/anbe.2003.2107

Messina FJ, Mitchell R (1989) Intraspecific variation in the eggspacing behavior of the seed beetle Callosobruchus maculatus. $\mathrm{J}$ Insect Behav 2:727-742. doi:10.1007/BF01049397

Messina FJ, Renwick JAA (1985) Ability of ovipositing seed beetles to discriminate between seeds with differing egg loads. Ecol Entomol 10:225-230. doi:10.1111/j.1365-2311.1985.tb00552.x

Messina FJ, Slade AF (1997) Inheritance of host-plant choice in the seed beetle Callosobruchus maculatus (Coleoptera : Bruchidae). Ann Entomol Soc Am 90:848-855

Messina FJ, Gardner SL, Morse GE (1991) Host discrimination by egg-laying seed beetles: causes of population differences. Anim Behav 41:773-779. doi:10.1016/S0003-3472(05)80343-4

Mitchell R (1990) Behavioral ecology of Callosobruchus maculatus. In: Fujii K, Gatehouse AMR, Johnson CD, Mitchell R, Yoshida $\mathrm{T}$ (eds) Bruchids and legumes: economics, ecology, and coevolution. Kluwer, The Netherlands, pp 317-330

Mitchell R (1991) The traits of a biotype of Callosobruchus maculatus (F) (Coleoptera: Bruchidae) from south India. J Stored Prod Res 27:221-224. doi:10.1016/0022-474X(91)90004-V

Nufio CR, Papaj DR (2001) Host marking behavior in phytophagous insects and parasitoids. Entomol Exp Appl 99:273-293. doi: 10.1023/A:1019204817341
Odeen A, Hastad O (2003) Complex distribution of avian color vision systems revealed by sequencing the SWS1 opsin from total DNA. Mol Biol Evol 20:855-861. doi:10.1093/molbev/msg108

Parr MJ, Tran BMD, Simmonds MSJ, Credland PF (1996) Oviposition behaviour of the cowpea seed beetle, Callosobruchus maculatus. Physiol Entomol 21:107-117. doi:10.1111/j. 1365-3032.1996.tb00842.x

Price T, Schluter D (1991) On the low heritability of life history traits. Evol Int J Org Evol 45:853-861. doi:10.2307/2409693

Protas ME, Hersey C, Kochanek D, Zhou Y, Wilkens H, Jeffery WR, Zon LI, Borowsky R, Tabin CJ (2006) Genetic analysis of cavefish reveals molecular convergence in the evolution of albinism. Nat Genet 38:107-111. doi:10.1038/ng1700

Rego C, Santos M, Matos M (2007) Quantitative genetics of speciation: additive and non-additive genetic differentiation between Drosophila madeirensis and Drosophila subobscura. Genetica 131:167-174. doi:10.1007/s10709-006-9128-z

Smith RH, Lessells CM (1985) Oviposition, ovicide and larval competition in granivorous insects. In: Sibly R, Smith RH (eds) Behavioural ecology. Blackwell Scientific, Oxford, pp 423-448

Stern DL, Orgogozo V (2008) The loci of evolution: how predictable is genetic evolution? Evol Int J Org Evol 62:2155-2177. doi: 10.1111/j.1558-5646.2008.00450.x

Stillwell RC, Wallin WG, Hitchcock LJ, Fox CW (2007) Phenotypic plasticity in a complex world: interactive effects of food and temperature on fitness components of a seed beetle. Oecologia 153:309-321. doi:10.1007/s00442-007-0748-5

Teotónio H, Matos M, Rose MR (2004) Quantitative genetics of functional characters in Drosophila melanogaster populations subjected to laboratory selection. J Genet 83:265-277. doi: 10.1007/BF02717896

Travisano M, Mongold JA, Bennett AF, Lenski RE (1995) Experimental tests of the roles of adaptation, chance and history in evolution. Science 267:87-90. doi:10.1126/science.7809610

Tucić N, Šešlija D (2007) Genetic architecture of differences in oviposition preference between ancestral and derived populations of the seed beetle Acanthoscelides obtectus. Heredity 98:268-273. doi:10.1038/sj.hdy.6800930

Tuda M, Iwasa Y (1998) Evolution of contest competition and its effect on host-parasitoid dynamics. Evol Ecol 12:855-870. doi: 10.1023/A: 1006550817371

Tuda M, Ronn J, Buranapanichpan S, Wasano N, Arnqvist G (2006) Evolutionary diversification of the bean beetle genus Callosobruchus (Coleoptera : Bruchidae): traits associated with storedproduct pest status. Mol Ecol 15:3541-3551. doi:10.1111/j. 1365-294X.2006.03030.x

Wasserman SS, Futuyma DJ (1981) Evolution of host plant utilization in laboratory populations of the southern cowpea weevil, Callosobruchus maculatus Fabricius (Coleoptera: Bruchidae). Evol Int J Org Evol 35:605-617. doi:10.2307/2408234

Wichman HA, Badgett MR, Scott LA, Boulianne CM, Bull JJ (1999) Different trajectories of parallel evolution during viral adaptation. Science 285:422-424. doi:10.1126/science.285.5426.422

Wood TE, Burke JM, Rieseberg LH (2005) Parallel genotypic adaptation: when evolution repeats itself. Genetica 123:157-170. doi:10.1007/s10709-003-2738-9

Yokoyama S, Radlwimmer FB, Blow NS (2000) Ultraviolet pigments in birds evolved from violet pigments by a single amino acid change. Proc Natl Acad Sci USA 97:7366-7371. doi: 10.1073/pnas.97.13.7366

Zhang JZ, Kumar S (1997) Detection of convergent and parallel evolution at the amino acid sequence level. Mol Biol Evol $14: 527-536$ 